\title{
KAJIAN PENGELOLAAN HUTAN MANGROVE DI DESA PULAU PAHAWANG KECAMATAN MARGA PUNDUH KABUPATEN PESAWARAN
}

\section{(STUDY OF MANGROVE FOREST MANAGEMENT IN THE PAHAWANG ISLAND VILLAGE MARGA PUNDUH DISTRICT PESAWARAN REGENCY)}

\author{
Rynaldo Davinsy $^{1)}$, Asihing Kustanti ${ }^{2)}$, dan Rudi Hilmanto ${ }^{2)}$ \\ ${ }^{1)}$ Mahasiswa Jurusan Kehutanan Fakultas Pertanian Universitas Lampung \\ ${ }^{2)}$ Dosen Jurusan Kehutanan Fakultas Pertanian Universitas Lampung \\ Jl. Soemantri Brojonegoro No. 1 Bandar Lampung \\ Email: rynaldo024@gmail.com \\ Phone: +6281930085504
}

\begin{abstract}
ABSTRAK
Pengelolaan hutan mangrove berkelanjutan adalah kegiatan yang tepat dalam pemanfaatan lahan dan hasil hutan di daerah pesisir. Kegiatan ini merupakan langkah baik untuk mengurangi kerusakan ekosistem mangrove dan mempertahankannya. Keadaan dan faktor yang menunjang dalam pengelolaan hutan mangrove sangat perlu diketahui untuk pengembangan selanjutnya. Tujuan penelitian ini adalah mengetahui bagaimana keadaan dan strategi pengembangan pengelolaan hutan mangrove. Penelitian dilakukan dengan metode wawancara pada instansi terkait dan ke masyarakat di Desa Pulau Pahawang pada bulan Januari-April 2015. Analisis data menggunakan analisis SWOT dan deskriptif. Hasil penelitian menunjukkan bahwa pengelolaan hutan mangrove sudah cukup baik, ini ditunjukan dengan nilai agresif $(1,22 ; 0,73)$, artinya strategi yang mengutamakan tindakan segera yaitu dengan memanfaatkan peluang dan mempertahankan kekuatan (growth oriented strategy). Strategi pengembangan harus saling mendukung antara pihak instansi terkait, pihak pengelola, dan masyarakat. Selain itu, kegiatan pengembangan tracking mangrove harus dilaksanakan melihat potensi hutan yang baik, adanya peraturan desa yang mendukung, dan respon masyarakat yang baik. Strategi yang dilakukan sebaiknya melibatkan Badan Pengelola Daerah Perlindungan Mangrove (BPDPM) dan masyarakat agar lebih optimal dalam pengembangannya. Keberlanjutan pengelolaan hutan mangrove seiring dengan meningkatnya pengetahuan aspek manajemen. Pengembangan prioritas lainnya adalah pemberian penyuluhan, pelatihan yang didampingi oleh tenaga ahli, dan pengembangan teknologi tepat guna.
\end{abstract}

Kata Kunci: SWOT, keberlanjutan, strategi pengembangan

\section{ABSTRACT}

Sustainable of mangrove forest management is a proper activity in land and forest product utilization at the coast area. This activity is decent step to relieve mangrove ecosystem demage and preserve it. The circumstances and the factors influenced mangrove forest still needs to be known for the continued in management. The purposes of this study were to determine how the mangrove forest management and development strategy of mangrove forest management. This study was conducted by interviewing the relevant agencies and key informans in the village of Pahawang island from January-April 2015. Datas processing was analyzed by SWOT and descriptive. Result showed that mangrove forest management in good enough with aggressive score $(1,22 ; 0,73)$, which means this strategy gives priority to immediate action by exploiting chances and maintaining strength (growth oriented strategy). 
Development strategy in the management have to support each other between relevant agencies, the managers, and society. Besides, tracking mangrove development has to be conducted considering the good forest potentials, with the existence of village regulations, and good response from society towards this plan. The strategy should be done by involving Mangrove Protected Area Management Agency and community to optimalize the development. Sustainability of mangrove forest management, should be accompanied with the advanced knowladge of management. Other priority development is by giving counseling, expert-accompanied training, and efficient technological development.

Key words: SWOT, sustainability, strategy of development

\section{PENDAHULUAN}

Hutan mangrove mempunyai karakteristik yang unik dibandingkan dengan formasi hutan lainnya. Keunikan hutan tersebut terlihat dari habitat tempat hidupnya, juga keanekaragaman flora, yaitu: Avicennia, Rhizophora, Bruguiera, dan tumbuhan lainnya yang mampu bertahan hidup disalinitas air laut, dan fauna yaitu kepiting, ikan, jenis Molusca, dan lain-lain. Hutan mangrove juga memiliki fungsi ekonomi, ekologi, dan sosial. Fungsi ekonomi yang ada di hutan mangrove yaitu penghasil kebutuhan rumah tangga, penghasil keperluan industri, dan penghasil bibit. Fungsi ekologisnya yaitu sebagai pelindung garis pantai, mencegah intrusi air laut, sebagai habitat berbagai jenis burung, dan lain-lain (Kustanti, 2011).

Hutan mangrove di Indonesia tersebar di beberapa provinsi di berbagai gugusan kepulauan. Luasan hutan mangrove di Indonesia lebih kurang 3,7 juta hektar yang merupakan hutan mangrove terluas yang ada di Asia dan bahkan di dunia (Kementerian Kehutanan, 2013). Menurut Cifor (2012), luas hutan mangrove di Indonesia telah mengalami penurunan 30-50\% dalam pada setengah abad terakhir ini karena pembangunan daerah pesisir, perluasan pembangunan tambak, abarasi air laut, dan penebangan yang berlebihan. Desa Pulau Pahawang, Kecamatan Marga Punduh, Kabupaten Pesawaran merupakan salah satu daerah yang memiliki hutan mangrove di Provinsi Lampung. Luasan hutan mangrove di Desa Pulau Pahawang ini pada tahun 1970-an berkisar 141,94 hektar (Harjono, 2010).

Hutan mangrove yang berada di Pulau Pahawang pada tahun 1970an pernah mengalami kerusakan akibat adanya ekploitasi hutan. Melihat keprihatinan hutan mangrove yang rusak pada tahun 2006 Lembaga Swadaya Masyarakat (LSM) Mitrabentala dan masyarakat merehabilitasi lahan mangrove tersebut hingga sekarang telah pulih.

Pengelolaan hutan mangrove di Desa Pulau Pahawang adalah kegiatan dalam pemanfaatan lahan dan hasil hutannya. Kemudian untuk melestarikan fungsi ekosistem mangrove diperlukan sebuah pendekatan yang rasional dalam pemanfaatannya dengan melibatkan masyarakat sekitar hutan mangrove, stakeholder, dan pemerintah. Menurut Kustanti, Nugroho, Durusman, dan Kusmana (2012) mengungkapkan bahwa masyarakat pesisir, stakeholder (Universitas Lampung), dan pemerintah daerah juga berperan penting dalam pengelolaan hutan mangrove. Namun, kegiatan pengelolaan dan strategi pengembangan dalam pengelolaan hutan mangrove di Desa Pulau Pahawang, Kecamatan Marga Punduh, Kabupaten Pesawaran masih perlu diketahui untuk pengembangan lanjutan dalam pengelolaannya.

\section{METODOLOGI PENELITIAN}

Penelitian ini dilakukan di Desa Pulau Pahawang Kecamatan Marga Punduh Kabupaten Pesawaran pada bulan Januari-April 2015. Alat yang digunakan pada penelitian adalah 
kamera, perekam suara, alat tulis kantor, Personal Computer $(P C)$, dan kuesioner. Sedangkan obyek dalam penelitian ini adalah masyarakat sekitar mangrove yang terpilih melalui snowball sampling 41 responden. Selain dari pihak masyarakat, dari berbagai pihak terkait melalui purposive sampling seperti tokoh masyarakat (tokoh adat, tokoh agama, dan tokoh masyarakat), LSM mitrabentala bagian divisi pemberdayaan masyarakat, pengguna mangrove seperti ibu PKK dan nelayan, kelompok masyarakat pelestari yaitu BPDPM dan guru. Pihak instansi yang terkait adalah Dinas Kelautan dan Perikanan (DKP) bagian pesisir dan pulaupulau kecil, Dinas Perkebunan dan Kehutanan (Disbunhut) bidang kehutanan, BPDPM yaitu ketua, dan aparatur Desa Pulau Pahawang yang terdiri dari Sekretaris Desa, Kepala Dusun Suak Buah, Kepala Dusun Penggetahan, Kepala Dusun Kalangan, Kepala Dusun Jeralangan, Kepala Dusun Pahawang 1, dan Kepala Dusun Cukuh Nyai.

Data primer pada penelitian ini berupa informasi dan keterangan mengenai hal-hal yang berkaitan dengan obyek penelitian seperti pengamatan langsung di lapangan dan pandangan dari pihak masyarakat maupun pihak pemerintah daerah. Data sekunder pada penelitian ini berupa data aspek sumberdaya, aksesibilitas menuju kawasan, dan kegiatan pengelolaan. Studi pustaka dan survey lapangan merupakan langkah awal dari penelitian ini, wawancara dan diskusi ini akan dilakukan dengan pihak yang terkait dan masyarakat yang menjadi responden dalam penelitian ini.

Brainstoming digunakan sebagai masukan dalam penyusunan strategi pengambilan keputusan pada faktor internal dan eksternal. Faktor internal dan eksternal ini dilakukan dengan melihat keadaan hutan mangrove dan persepsi masyarakat juga pandangan pemerintah terhadap keadaan pengelolaan hutan mangrove. Analisis faktor strategi meliputi analisis faktor internal dan faktor external. Analisis faktor internal menggunakan matriks faktor strategi internal (internal factor analysis summary/IFAS). Sedangkan untuk analisis faktor eksternal menggunakan faktor strategi eksternal (external factor analysis summary/EFAS). Berdasarkan matriks IFAS dan EFAS selanjutnya dibuat diagram SWOT (Rangkuti, 2014).

\section{a. Pendekatan Kualitatif Matriks SWOT}

Tabel 1. Lembar kerja matriks SWOT.

\begin{tabular}{|c|l|l|}
\hline \multicolumn{1}{|c|}{ IFAS } & $\begin{array}{c}\text { KEKUATAN (S) } \\
\text { Menentukan faktor-faktor yang } \\
\text { merupakan kekuatan internal }\end{array}$ & $\begin{array}{l}\text { KELEMAHAN (W) } \\
\text { Menentukan faktor-faktor yang } \\
\text { merupakan kelemahan internal }\end{array}$ \\
\hline $\begin{array}{l}\text { PELUANG (O) } \\
\text { Menentukan faktor-faktor } \\
\text { yang merupakan peluang } \\
\text { eksternal }\end{array}$ & $\begin{array}{l}\text { STRATEGI S-O } \\
\text { Menghasilkan strategi yang } \\
\text { menggunakan kekuatan untuk } \\
\text { memanfaatkan peluang }\end{array}$ & $\begin{array}{l}\text { STRATEGI W-O } \\
\text { Menghasilkan strategi yang } \\
\text { meminimalkan kelemahan untuk } \\
\text { memanfaatkan peluang }\end{array}$ \\
\hline $\begin{array}{l}\text { ANCAMAN (T) } \\
\text { Menentukan faktor-faktor } \\
\text { yang merupakan ancaman } \\
\text { eksternal }\end{array}$ & $\begin{array}{l}\text { STRATEGI S-T } \\
\text { Menghasilkan strategi yang } \\
\text { menggunakan kekuatan untuk } \\
\text { mengatasi ancaman }\end{array}$ & $\begin{array}{l}\text { STRATEGI W-T } \\
\text { Menghasilkan strategi yang } \\
\text { meminimalkan kelemahan dan } \\
\text { menghindari ancaman }\end{array}$ \\
\hline
\end{tabular}

Sumber : Patang (2012), Wiharyanto dan Laga (2010), Rangkuti (2014).

\section{b. Pendekatan Kuantitatif Analisis SWOT}

Data SWOT kualitatif di atas dapat dikembangkan secara kuantitaif melalui perhitungan Analisis SWOT. Perhitungan yang dilakukan melalui tiga tahap, yaitu: (1). Melakukan perhitungan rating (a) pemberian rating dilakukan dengan melihat persepsi atau pandangan dari masyarakat, dengan pemberian nilai 1-4 untuk masing-masing peubah dengan pengaruh kecil, sedang, besar dan sangat besar (Rangkuti, 2014 dan Sitompul, 2011). Bobot (b) dengan 
cara melihat persepsi dan pandangan dari berbagai pihak terkait dan lapangan, dilakukan dengan memberikan nilai $1,2,3, \ldots \mathrm{n} \%$ (sebanyak jumlah peubah internal maupun eksternal) berdasarkan tingkat kepentingannya dibanding peubah lain (Rangkuti, 2014 dan Sitompul, 2011). Skor perkalian rating dan bobot $(\mathrm{c}=\mathrm{a} \mathrm{x}$ b) pada setiap faktor S-W-O-T, (2). Melakukan pengurangan antara jumlah total faktor $\mathrm{S}$ dengan $\mathrm{W}(\mathrm{x})$ dan faktor $\mathrm{O}$ dengan $\mathrm{T}$ (y), (3). Mencari posisi organisasi yang ditunjukkan oleh titik (x,y) pada kuadran SWOT (Rangkuti, 2014 dan Sitompul, 2011).

Setelah analisis SWOT pengambilan keputusan telah didapatkan kemudian pengolahan dan analisis data dilakukan dengan menggunakan metode analisis deskriptif, yaitu mentransformasikan data hasil analisis SWOT ke dalam data yang mudah dimengerti dan ditafsirkan serta menyusun dan menyajikan supaya menjadi suatu formasi. Menurut Rangkuti (2014), Penilaian pendapat responden yaitu: a. Tahu apabila mengerti, b. Sedikit tahu apabila hanya berkata dengan ragu, c. Tidak tahu apabila tidak dapat menjawab.

\section{HASIL DAN PEMBAHASAN}

\section{Karakteristik Responden}

Responden masyarakat yang sesuai dengan snowball sampling berjumlah 41, yang terdiri dari 17 perempuan dan 24 laki-laki dengan rentang umur 18-60 tahun (gambar 1).

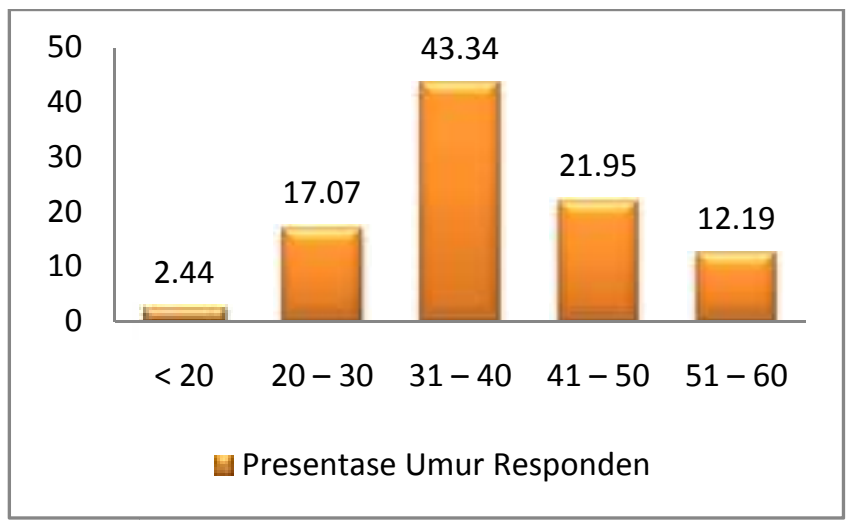

Sumber: Hasil Penelitian (2015).

Gambar 1. Sebaran umur responden di Desa Pulau Pahawang.

Tingkat pendidikan responden yang mendominasi hanya sekolah menengah pertama (SMP), dan yang kedua sekolah dasar (SD). Hal ini dapat dilihat pada Gambar 2.

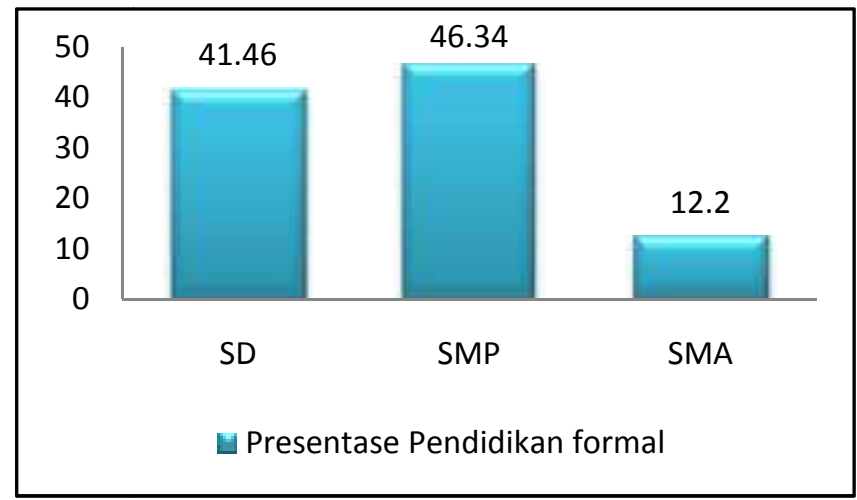

Sumber: Hasil Penelitian (2015).

Gambar 2. Sebaran pendidikan formal responden di Desa Pulau Pahawang. 
Jenis pekerjaan yang beragam yang paling mendominasi adalah Ibu Rumah Tangga (gambar 3). Kemudian ekosistem mangrove yang pekerjaannya sebagai nelayan sedikit karena telah banyak keramba ikan yang dibuat.

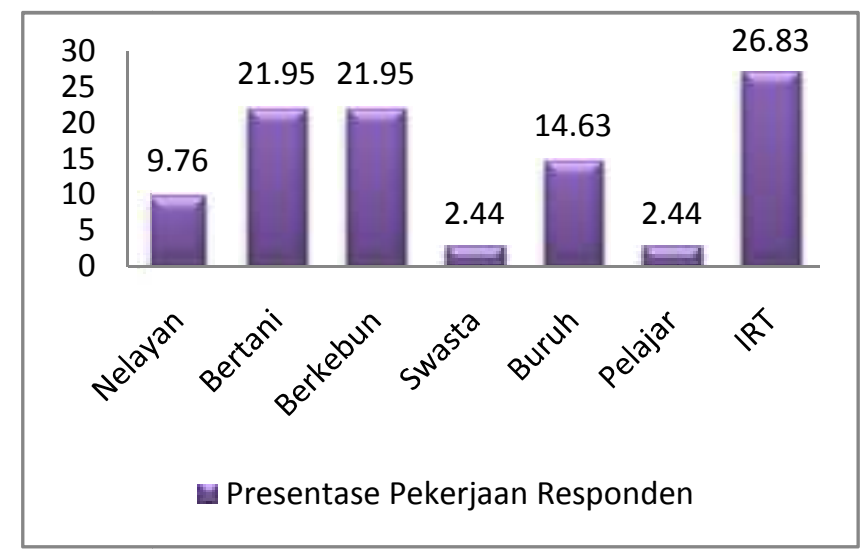

Sumber: Hasil Penelitian (2015).

Gambar 3. Sebaran pekerjaan responden di Desa Pulau Pahawang.

Tingkat ekonomi masyarakat menurut data dari Departemen Kehutanan (2001) dalam Novianty (2011) mengatakan bahwa, faktor keinginan manusia (masyarakat) dalam mengelola hutan mangrove maupun merusaknya sangatlah besar. Menurut Pradana, Nirwani, dan Suryono (2013), aspek ini merupakan kegiatan yang sangat mempengaruhi kinerja dari masyarakat dalam ikut serta untuk pengelolaan hutan mangrove. Rata-rata masyarakat yang ada di Desa Pulau Pahawang bekerja sebagai petani, pekebun, nelayan, dan lainnya. Ekonomi dapat dikatakan baik karena masyarakatnya bekerja, akan tetapi tidak seimbang dengan pengeluaran masyarakat. Menurut Kustanti, dkk (2012) perkembangan ekonomi dapat dilakukan dengan pemanfaatan potensi yang dihasilkan oleh hutan mangrove kayu non berupa budidaya ikan air tawar, lebah madu, berbagai sumber pakan, dan gula nira.

\section{Faktor Internal}

1. Pengetahuan Masyarakat Tentang Hutan Mangrove

Sebanyak $89 \%$ responden mengatakan bahwa mereka mengetahui bagaimana keadaan fisik hutan mangrove. Menurut Subhan (2014) dalam pengelolaan hutan mangrove tidak lepas terhadap respon masyarakat dalam mendukung rencana pengelolaan, akan tetapi pentingnya pengetahuan juga berpengaruh. Pengelolaan hutan mangrove di Desa Pulau Pahawang sangat didukung oleh masyarakat hal ini dibuktikan dari hasil kuesioner yaitu $67 \%$ responden tidak memperbolehkan untuk mengambil kayu mangrove meskipun di areal pemanfaatan dengan alasan untuk melestarikan hutan tersebut dan untuk menjaga daerah mereka.

\section{Pemahaman Masyarakat Tentang Pengelolaan Hutan Mangrove}

Hasil penelitian memperlihatkan bahwa masyarakat yang tahu tentang pengelolaan hanya $10 \%$, sebagian masyarakat $58 \%$ hanya sedikit tahu, dan bahkan lebih dari $32 \%$ masyarakat tidak mengetahuinya. Menurut Kustanti, dkk (2012), peningkatan suatu pemahaman yang sama tentang manfaat dan fungsi hutan mangrove antara pemangku kepentingan dan pihak terkait seperti stakeholder, masyarakat, institusi pendidikan tinggi lokal, dan LSM sangat diperlukan. Kemudian 67\% masyarakat sedikit mengetahui manfaat dari pengelolaan. 
Menurut Tambunan (2005) mengatakan bahwa, keterlibatan dan juga pemahaman akan pentingnya pengelolaan harus ada dalam kelompok masyarakat yang berada di sekitar mangrove. Pendapat masyarakat, bahwa menyetujui apabila pengelolaan hutan mangrove tersebut dilakukan oleh badan organisasi terkait dengan melibatkan masyarakatnya. Hal ini dibuktikan dengan presentase persetujuan sebanyak $89 \%$. Saat ini banyak pihak yang telah ikut terlibat dalam pengelolaan hutan mangrove di Pulau Pahawang ini.

\section{Aspek Sumberdaya}

Selain peranan ekologisnya dalam menahan abrasi air laut, hutan mangrove juga berperan sebagai pembentuk iklim mikro di sekitarnya (dikemukakan 100\% responden). Selain pembentuk iklim mikro menurut (Bann, 1998 dalam Huda, 2008), mengungkapkan aspek ekologi lain dari mangrove meliputi stabilitas garis pantai, sedimen, perlindungan dan produktifitas biomassa, sumber plasma nutfah, rekreasi atau wisata, memancing dan produkproduk hutan. Aspek ekologi lain dari hutan mangrove yang tidak kalah penting adalah menjadi tempat tinggal atau habitat makro dan mikro organisme lainnya. Kelompok fauna daratan/terestrial yang umumnya menempati bagian atas pohon mangrove, terdiri atas: insekta, ular, primata dan burung (Muhaerin, 2008).

Hasil wawancara dari DKP mengatakan bahwa keadaan hutan mangrove Pulau Pahawang termasuk dalam kategori sedang dibandingkan dengan pengelolaan daerah pesisir lainnya. Ditinjau dari aspek sumberdaya dalam pengelolaan hutan mangrove, ada beberapa pokok penting yang menjadi keunggulan yang mendukungnya sebagai usaha yang layak untuk dikembangkan. Hasil kuesioner juga mengungkapkan tanaman yang mereka tanam terdiri dari berbagai macam tanaman seperti kelapa (Cocos nucifera), cengkeh (Syzygium aromaticum), kakao (Theobroma kakao), jengkol (Pithecellobium lobatum), dan pohon-pohon lainnya. Menurut Sitompul (2011), mengungkapkan bahwa biasanya dalam suatu kawasan hutan yang terdapat masyarakat terdiri dari bermacam-macam jenis tanaman semusim dengan sistem agroforestri. Selain berkebun mereka juga ada yang menjadi nelayan di laut, dengan mencari ikan, udang, dan kepiting.

\section{Aspek Manajemen}

a. Aspek Perencanaan

Tingkat ini masyarakat telah cukup aktif berpartisipasi dalam hal perencanaan. Hasil kuesioner menunjukan adanya yang bukti sikap masyarakat yang ikut membahas perencanaan pengelolaan dengan presentase $67 \%$, dan siap untuk melestarikan hutan mangrove tersebut sebanyak 78\%. Menurut Novianty (2011), menjelaskan bahwa pelibatan masyarakat dalam perencanaan perlu diperhatikan, karena keterlibatan masyarakat akan menciptakan rasa tanggung jawab bersama sehingga diperoleh hasil kerja yang terbaik.

\section{b. Aspek Pelaksanaan}

Persentase responden yang sangat aktif dalam pelaksanaan kegiatan pelestarian hutan mangrove sebesar 20\%. Responden ini merupakan anggota dari badan pengelola daerah perlindungan mangrove. Responden yang menyatakan aktif dalam pelaksanaan sebanyak $57 \%$. Sedangkan $23 \%$ responden menyatakan tidak aktif dalam pengelolaan, ini merupakan responden wanita/ibu-ibu. Beberapa bentuk pelibatan masyarakat antara lain: pelatihan mangrove seperti pelatihan pengelolaan dan pelatihan hasil hutan non kayu, penanaman mangrove secara gotong royong dengan sistem padat karya (Subhan, 2014). Sependapat dengan penelitian tersebut menurut Kustanti, dkk (2012), menyatakan peningkatan pengetahuan dan keterampilan dalam pengelolaan mangrove secara berkala, akan berpengaruh terhadap masyarakat, sehingga mereka tahu manfaat dan fungsi hutan mangrove bagi kehidupan, juga mengenal berbagai tanaman mangrove. 
c. Aspek Pengawasan

Kegiatan pelaksanaan ini telah dilakukan di Pulau Pahawang, seperti pensosialisasian apabila ada masyarakat lain yang merusak hutan, hal ini juga mendapatkan presentase yang sangat baik yaitu $100 \%$ mendukung. Saat ini kegiatan pengawasan hutan mangrove masih seperti pengawasan biasa. Menurut Kaimuddin (2008), mengungkapkan bahwa aspek pengawasan dapat berjalan dengan baik apabila terdapatnya perlengkapan yang memadai dan pengetahuan yang cukup. Kemudian dalam peranannya masyarakat berperan dalam menjaga kelestarian hutan tersebut, meski mereka juga kadang-kadang saja mengikuti pelaksanaannya. Menurut Kustanti, dkk (2012) mengungkapkan pengawasan yang dapat dilakukan adalah patroli rutin baik dari sisi dan masyarakat dari Dinas Kehutanan di sekitar hutan.

\section{Faktor Eksternal}

\section{Aksesibilitas Menuju Kawasan}

Aksesibilitas merupakan salah satu kunci utama yang akan mendukung keberhasilan pengembangan pada suatu kawasan, karena akan menghubungkan wilayah pengembangan dengan daerah luar (Muhaerin, 2008). Menurut hasil wawancara, karena daerah yang cukup terjangkau dari Kota Bandar Lampung maka program yang akan dilaksanakan untuk kedepannya adalah rehabilitasi hutan mangrove, dengan harapan Desa Pulau Pahawang ini menjadi suatu obyek wisata minapolitan. Mendukung rencana wisata tersebut juga stakeholder juga ingin mengembangkan tracking mangrove di daerah Pulau Pahawang. Sependapat dengan diatas menurut Pariyono (2008), aksesibilitas yang baik haruslah didukung dengan kondisi lokasi yang menjadi obyek wisata alam yang akan disuguhkan seperti adanya fasilitas yang baik.

Beberapa responden instansi dan organisasi BPDPM, LSM Mitrabentala juga sangat mendukung pencapai yang direncanakan ini. Apabila akan dikembangkan menjadi kawasan ekowisata, maka perlu adanya sosialisasi program atau penyuluh konservasi secara berkelanjutan kepada masyarakat. Menurut Muhaerin (2008), Hal ini perlu dilakukan agar masyarakat dapat berpartisipasi dalam kegiatan pembangunan yang dilakukan. Selain itu, dengan adanya kegiatan sosialisasi ini dapat meningkatkan pemahaman masyarakat mengenai konservasi.

\section{Kegiatan Pengelolaan}

Kegiatan yang dilakukan oleh sebagian besar masyarakat yaitu bertani dan berkebun. Selain masyarakat responden instansi juga berlatar belakang sebagai staff di instansi mereka. Pengelolaan yang dilakukan DKP merupakan pengelolaan yang berbasis lingkungan yaitu kegiatan yang berhubungan dengan pesisir lautnya. Namun, dalam pengelolaannya DKP sering mengalami tumpang tindih dengan Disbunhut, seperti apabila ingin memberikan penyuluhan dan pelatihan kepada masyarakat kedua instansi saling mengambil alih materi yang ingin diberikan hal ini dikarenakan kurangnya koordinasi antar instansi. Kurangnya koordinasi yang ada pada setiap stakeholder akan berpengaruh terhadap pengelolaan hutan mangrove (Wiharyanto dkk, 2010).

Menurut Kustanti, dkk (2012), kegiatan inspeksi yang dilakukan oleh pihak terkait harus agar dapat mengendalikan aktivitas mereka. Selain pemberian materi juga pendampingan hutan mangrove di Pulau Pahawang sekarang telah mempunyai peraturan desa tentang perlindungan hutan mangrove No. 02/007/Perdes-phm/XI/2006 seperti pelarangan merusak hutan yang berisi tentang pemberian hukuman bagi pelanggar dan, pembagian zonasi hutan yang meliputi: zona inti, zona pemanfaatan, dan zona penyangga. 


\section{Analisis Faktor Internal dan Eksternal}

1. Peubah strategi internal memiliki pengaruh terhadap pengembangan pengelolaan hutan mangrove (Rangkuti, 2014) analisis kekuatan (strength) disajikan pada tabel 2. Peubah tertinggi yaitu keadaan hutan mangrove yang terjaga kelestariannya nilai pengaruh yaitu 1,00.

Tabel 2. Matriks faktor internal (unsur kekuatan/strength).

\begin{tabular}{cllccc}
\hline No & \multicolumn{2}{c}{ Unsur Kekuatan/ Strength } & Bobot & Rating & Skor \\
\hline 1 & $\begin{array}{l}\text { Keadaan hutan mangrove yang terjaga } \\
\text { kelestariannya. }\end{array}$ & 0,25 & 4 & 1,00 \\
2 & $\begin{array}{l}\text { Terdapatnya BPDPM yang didampingi oleh LSM } \\
\begin{array}{l}\text { Mitrabentala. } \\
3\end{array}\end{array}$ & $\begin{array}{l}\text { Penerapan pendidikan ektrakurikuler pada sekolah } \\
\text { dasar tentang pengelolaan hutan mangrove. }\end{array}$ & 0,19 & 3 & 0,92 \\
4 & $\begin{array}{l}\text { Adanya pembagian zonasi pada hutan mangrove. } \\
5\end{array}$ & 0,21 & 3 & 0,63 \\
& $\begin{array}{l}\text { Pengelolaan hasil hutan nonkayu pada hutan } \\
\text { mangrove. }\end{array}$ & 0,12 & 2 & 0,24 \\
\hline & Total & $\mathbf{1 , 0 0}$ & & $\mathbf{3 , 3 6}$ \\
\hline
\end{tabular}

Sumber: Data Olahan (2015).

2. Peubah strategi internal memiliki pengaruh terhadap pengembangan pengelolaan hutan mangrove (Rangkuti, 2014) analisis kelemahan (weakness) disajikan pada tabel 3. Menurut Muhaerin (2008), mengungkapkan bahwa tingkat partisipasi masyarakat akan pengelolaan pada ekosistem hutan mangrove lemah dikarenakan kesejahteraan masyarakat dan pola pikir.

Tabel 3. Matriks faktor internal (unsur kelemahan/weakness).

\begin{tabular}{clccc}
\hline No & \multicolumn{1}{c}{ Unsur Kelemahan/Weakness } & Bobot & Rating & Skor \\
\hline 1 & $\begin{array}{l}\text { Tingkat partisipasi masyarakat untuk ikut mengelola } \\
\text { hutan mangrove kurang. }\end{array}$ & 0,27 & 3 & 0,81 \\
2 & $\begin{array}{l}\text { Kurangnya teknologi tepat guna untuk pengelolaan } \\
\text { hutan mangrove. }\end{array}$ & 0,13 & 1 & 0,13 \\
3 & $\begin{array}{l}\text { Kurangnya pelatihan/penyuluhan tentang pengelolaan } \\
\text { hutan mangrove. }\end{array}$ & 0,22 & 2 & 0,44 \\
4 & $\begin{array}{l}\text { Pemahaman dan pengetahuan tentang pengelolaan } \\
\text { hutan mangrove masih kurang. } \\
5\end{array}$ & 0,19 & 2 & 0,38 \\
Minat masyarakat kurang dalam hal pelaksanaan di & 0,19 & 2 & 0,38 \\
\hline & Total & $\mathbf{1 , 0 0}$ & $\mathbf{2 , 1 4}$ \\
\hline
\end{tabular}

Sumber: Data Olahan (2015).

3. Peubah strategi internal memiliki pengaruh terhadap pengembangan pengelolaan hutan mangrove (Rangkuti, 2014) analisis peluang (opportunity) disajikan pada tabel 4. Rehabilitasi lahan dan hutan adalah upaya untuk memulihkan, mempertahankan, dan meningkatkan fungsi hutan dan lahan (Direktorat Jenderal Rehabilitasi Lahan dan Perhutanan Sosial, 2005 dalam Subhan, 2014). 
Tabel 4. Matriks faktor eksternal (Unsur Peluang/Opportunity).

\begin{tabular}{clcccc}
\hline No & \multicolumn{1}{c}{ Unsur Peluang/Opportunity } & Bobot & Rating & Skor \\
\hline 1 & $\begin{array}{l}\text { Adanya rencana rehabilitasi hutan mangrove di } \\
\text { Dusun 4 Pulau Pahawang. }\end{array}$ & 0,31 & 3 & 0,93 \\
2 & $\begin{array}{l}\text { Peraturan desa tentang pengelolaan hutan mangrove. } \\
\text { Potensi pengembangan wisata konservasi mangrove }\end{array}$ & 0,21 & 3 & 0,24 \\
& $\begin{array}{l}\text { (Tracking) besar. } \\
\text { Respon Masyarakat dalam mendukung pelestarian } \\
\text { hutan mangrove. }\end{array}$ & 0,11 & 2 & 0,96 \\
5 & Aksesibiltitas yang menarik untuk dikunjungi. & 0,13 & 2 & 0,26 \\
\hline$\quad$ Total & $\mathbf{1 , 0 0}$ & & $\mathbf{3 , 0 0}$ \\
\hline
\end{tabular}

Sumber: Data Olahan (2015).

4. Peubah strategi internal memiliki pengaruh terhadap pengembangan pengelolaan hutan mangrove (Rangkuti, 2014) analisis ancaman (threath) disajikan pada tabel 5. Zona Inti adalah suatu kawasan yang mengandung atribut biologis yang sangat penting bagi kelangsungan hidup ekosistem (Kustanti dkk, 2011).

Tabel 5. Matriks faktor eksternal (Unsur Ancaman/Threath).

\begin{tabular}{|c|c|c|c|c|}
\hline No & Unsur Ancaman/Threath & Bobot & Rating & Skor \\
\hline 1 & Terganggunya zonasi inti hutan mangrove. & 0,28 & 3 & 0,84 \\
\hline 2 & $\begin{array}{l}\text { Kepedulian masyarakat akan kebersihan lingkungan } \\
\text { disekitar dermaga. }\end{array}$ & 0,23 & 2 & 0,46 \\
\hline 3 & Minat masyarakat kurang & 0,24 & 3 & 0,72 \\
\hline 4 & Pertumbuhan Penduduk di Desa Pulau Pahawang. & 0,13 & 1 & 0,13 \\
\hline \multirow[t]{2}{*}{5} & adanya pihak yang ingin membuat tambak. & 0,12 & 1 & 0,12 \\
\hline & Total & 1,00 & & 2,27 \\
\hline
\end{tabular}

Sumber: Data Olahan (2015).

\section{Diagram SWOT Pengelolaan Hutan Mangrove}

Berdasarkan faktor-faktor internal yaitu kekuatan dan kelemahan juga faktor-faktor eksternal yaitu peluang dan ancaman yang telah dijelaskan diatas maka diagram SWOT dapat disusun. Nilai-nilai pengaruhnya didasarkan pada skor yang sudah diketahui, masing-masing akan dihitung selisihnya yaitu dengan cara menghitung selisih total nilai pengaruh kekuatan terhadap kelemahan serta nilai pengaruh peluang diselisihkan terhadap nilai ancaman.

Hasil analisis menunjukkan bahwa total nilai pengaruh peubah strategi internal memiliki selisih nilai yaitu sebesar 1,22. Demikian juga untuk peubah eksternal memiliki selisih dengan nilai 0,73. Kemudian menggabungkan kedua nilai selisih antara kekuatan terhadap kelemahan serta peluang terhadap ancaman, maka diperoleh sebuah titik koordinat, yaitu titik koordinat $(1,22 ; 0,73)$. Menggambarkan titik dimaksud pada diagram SWOT maka diketahui berada pada kuadran/sel 1 seperti pada gambar 1. 


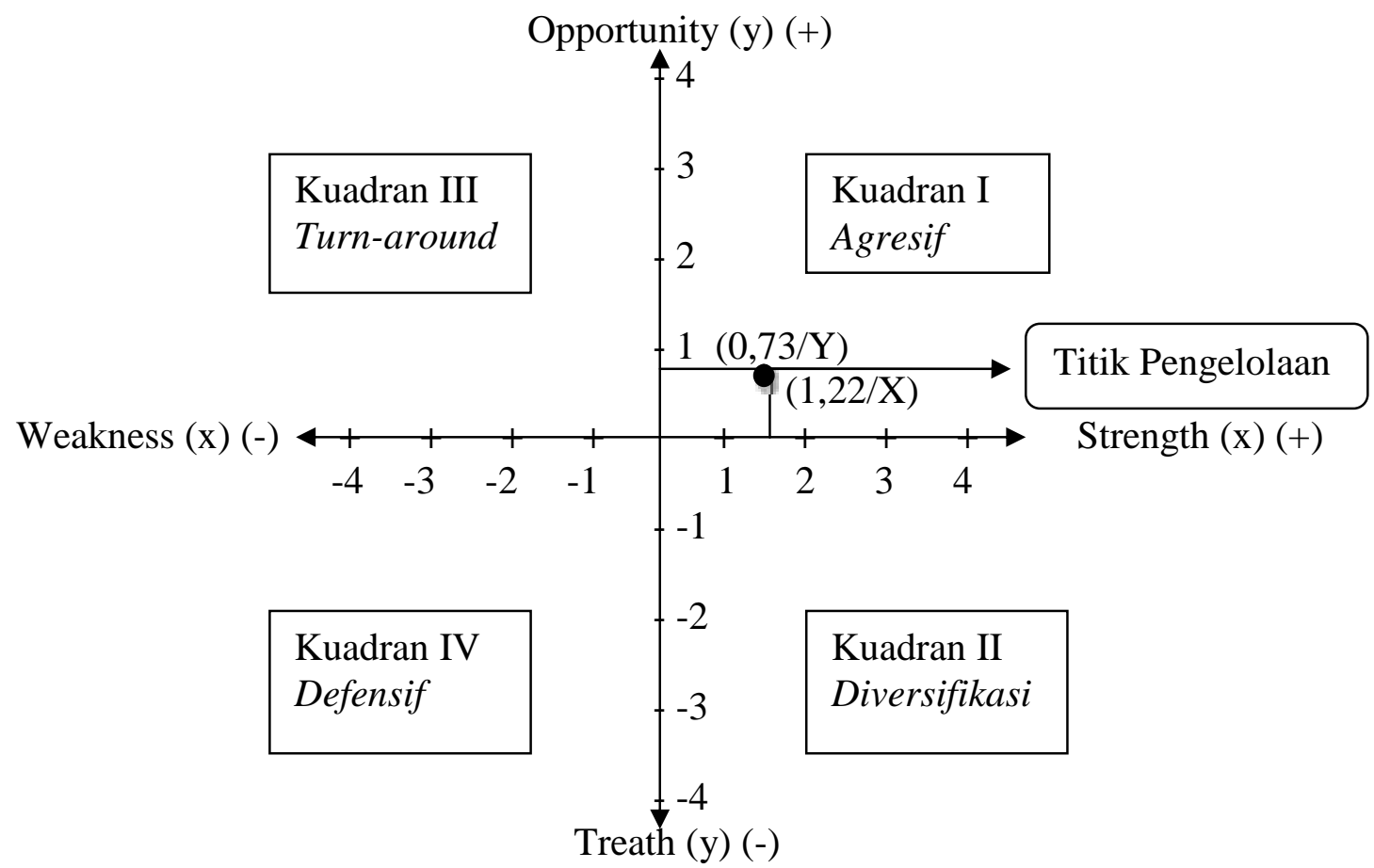

Gambar 4. Kuadran 1 adalah strategi pengembangan pengelolaan hutan mangrove di Desa Pulau Pahwang Kecamatan Marga Punduh Kabupaten Pesawaran.

Menurut Subhan (2014), pengelolaan hutan mangrove seperti pada kuadran di atas menunjukan situasi yang menguntungkan. Pengelolaan mangrove sekarang memiliki peluang dan kekuatan sehingga dapat saling memanfaatkan yang ada. Strategi yang harus diterapkan dalam kondisi ini adalah mendukung kebijakan pertumbuhan yang agresif/growth oriented strategy (Rangkuti, 2014). Selain dari cara kuantitatif, pendekatan secara kualitatif juga dilakukan.

\section{Strategi Pengembangan Pengelolaan Hutan Mangrove}

Kuadran 1 definisinya pengelolaan hutan mangrove dalam kondisi yang prima dan mantap sehingga sangat dimungkinkan untuk terus melakukan ekspansi, memperbesar pertumbuhan dan meraih kemajuan secara maksimal (Sitompul, 2011). Sedangkan menurut Kustanti dkk. (2012), strategi agresif dalam pengelolaan terpadu hutan mangrove di Lampung Mangrove Center Desa Margasari Kecamatan Labuhan Maringgai Provinsi Lampung adalah strategi yang mengutamakan tindakan segera dengan mendorong kegiatan dalam memanfaatkan peluang dan menekan ancaman dari elemen lingkungan.

Berarti dalam strateginya adalah pengelolaan yang dilakukan sekarang telah cukup baik namun pertumbuhan pengetahuan juga harus seimbang (Sitompul, 2011). Strategi pengelolaan tersebut harus saling mendukung antar pihak instansi terkait dengan pihak pengelola, dan masyarakat. Selain itu, pengembangan tracking mangrove harus dilaksanakan melihat potensi hutan yang ada sangat baik, adanya peraturan desa, dan respon masyarakat yang baik akan rencana ini. Pengembangan yang dilakukan sebaiknya melibatkan BPDPM dan masyarakat agar dapat lebih optimal pengembangannya. Hal ini didukung oleh pendapat dari berbagai instansi yang ingin membuat rencana pengembangan wilayah tracking mangrove.

Strategi-strategi pengembangan prioritas yang dapat dilakukan adalah pemberian materi penyuluhan tentang pengelolaannya di terutama planning, organizing, actuating, and controling (POAC), karena masyarakatnya banyak belum faham akan pengelolaan seperti apa 
yang ingin dilakukan di wilayah mereka. Pemberian pelatihan ini masyarakat didampingi oleh tenaga ahli agar masyarakat benar-benar tahu dan paham mengenai cara pelestarian kawasan mangrove di daerah mereka (Subhan, 2014). Pengelolaan hutan mangrove yang dilakukan oleh BPDPM sudah berjalan secara optimal, akan tetapi pelibatan masyarakat harus lebih ditekankan, sependapat dengan pernyataan diatas menurut Novianty (2011), masyarakat harus lebih diikutsertakan agar pengelolaan dapat lebih optimal.

\section{KESIMPULAN}

Pengelolaan hutan mangrove di Desa Pulau Pahawang Kecamatan Marga Punduh Kabupaten Pesawaran sudah cukup baik dengan nilai agresif yaitu $(1,22 ; 0,73)$. Pengelolaan hutan mangrove di Pulau Pahawang saat ini telah ada badan organisasi Badan Pengelola Daerah Perlindungan Mangrove (BPDPM), LSM Mitrabentala. Seluruh masyarakat telah mengetahui adanya badan organisasi yang mengelola hutan mangrove di daerah mereka.

Strategi yang harus diterapkan dalam kondisi ini adalah mendukung kebijakan pertumbuhan yang agresif (growth oriented strategy). Strategi pengembangan pengelolaan tersebut harus saling mendukung antar pihak instansi terkait, pihak pengelola, dan masyarakat. Selain itu, pengembangan tracking mangrove harus dilaksanakan melihat potensi hutan yang baik, adanya peraturan desa, dan respon masyarakat yang baik akan rencana ini. Hal ini didukung oleh pendapat dari instansi seperti DKP, Disbunhut, dan aparatur desa. Keberlanjutan suatu pengelolaan pada hutan mangrove harus diiringi dengan meningkatnya pengetahuan akan pentingnya manajemen. Selain secara umum, strategi prioritas yang dapat dilakukan adalah pemberian materi penyuluhan, pelatihan yang didampingi oleh tenaga ahli, dan pengembangan teknologi tepat guna.

\section{DAFTAR PUSTAKA}

Center for International Forestry Research (Cifor). 2012. Mangrove adalah salah satu hutan terkaya karbon di kawasan tropis. Jurnal brief. 12(1):1.

Harjono. 2010. Hutan mangrove di Pulau Pahawang. Diunduh pada tanggal 10 april 2014. http://hutan-mangrove-di-pulau-pahawang.com.

Huda, N. 2008. Strategi kebijakan pengelolaan mangrove berkelanjutan di Wilayah Pesisir Kabupaten Tanjung Jabung Timur Jambi. Tesis. Program Pascasarjana Universitas Diponegoro Semarang. $109 \mathrm{p}$

Kaimuddin. 2008. Studi kelembagaan lokal masyarakat dalam pembangunan hutan mangrove di desa munte kecamatan bone-bone (kajian base line kelembagaan untuk program adaptasi terhadap perubahan iklim global). Jurnal hutan dan masyarakat. 3(1):001— 110.

Kementerian Kehutanan. 2013. Luasan hutan mangrove di Indonesia. Diunduh pada tanggal 4 april 2014. hhtp://kementerian kehutanan.com.

Kustanti, A. 2011. Manajemen Hutan Mangrove. Buku. IPB Press. Bogor. 248 p.

Kustanti, A., B. Nugroho., D. Durusman., dan C. Kusmana. 2012. Integrated management of mangroves ecosystem in lampung mangrove center (LMC) East Lampung Regency, Indonesia. Journal of coastal develpopment. 15(2):209-216.

Muhaerin, M. 2008. Kajian sumberdaya ekosistem mangrove untuk pengelolaan ekowisata di Estuari Perancak, Jembrana, Bali. Tesis. Departemen Manajemen Sumberdaya Perairan Fakultas Perikanan Dan Ilmu Kelautan Institut Pertanian Bogor. 60 p. 
Novianty, R., S. Sukajaya., dan D. J. Prihadi. 2011. Identifikasi kerusakan dan upaya rehabilitasi ekosistem mangrove di Pantai Utara Kabupaten Subang. Jurnal Akuatika. 2(2): $1-9$.

Pariyono. 2006. Kajian potensi kawasan mangrove dalam kaitannya dengan pengelolaan Wilayah Pantai di Desa Panggung, Bulakbaru, Tanggultlare, Kabupaten Jepara. Tesis. Program Pascasarjana Megister Manajemen Sumberdaya Pantai Universitas Diponegoro Semarang. $89 \mathrm{p}$.

Patang. 2012. Analisis srategi pengelolaan hutan mangrove (kasus di Desa Tongke - Tongke Kabupaten Sinjai). Jurnal agrisistem. 8(2):101.

Pradana, Oky. Y., Nirwani., dan Suryono. 2013. Kajian bioekologi dan strategi pengelolaan ekosistem mangrove: Studi Kasus di Teluk Awur Jepara. Journal Of Marine Research. 2(1):54-61.

Rangkuti,F. 2014. Analisis SWOT: teknik membedah kasus bisnis (reorientasi konsep perencanaan strategis untuk menghadapi abad 21). Buku. PT.Gramedia Pustaka Utama. Jakarta. 246 p.

Sitompul, M. 2011. Kajian pengelolaan hutan kemenyan (Styrax sp.) di Kabupaten Humbang Hasundutan, Provinsi Sumatera Utara. Tesis. Program Pascasarjana Intitut Pertanian Bogor. 93 p.

Subhan, M. 2014. Analisis tingkat kerusakan dan strategi pengelolaan mangrove Di Kawasan Suaka Perikanan Gili Ranggo Teluk Seriwe Kabupaten Lombok Timur Nusa Tenggara Barat. Tesis. Program Studi Ilmu Lingkungan Program PascasarjanaUniversitas Udayana Denpasar. 95 p.

Tambunan, R., R. H. Harahab., dan Z. Lubis. 2005. Pengelolaan hutan mangrove di Kabupaten Asahan (studi kasus partisipasi masyarakat dalam pengelolaan hutan mangrove di Kecamatan Lima Puluh Kabupaten Asahan). Jurnal study pembangunan. 1(1):55-69.

Wiharyanto, D., dan A. Laga. 2010. Kajian pengelolaan hutan mangrove di kawasan konservasi Desa Mamburungan Kota Tarakan Kalimantan Timur. Jurnal media sains. 2(1):10-17. 